\title{
APPLICATION OF 3-D VELOCITY MODELS AND RAY TRACING IN DOUBLE DIFFERENCE EARTHQUAKE LOCATION ALGORITHMS: APPLICATION TO THE MYGDONIA BASIN (NORTHERN GREECE)
}

\author{
O.C. Galanis, C.B. Papazachos, P.M. Hatzidimitriou and E.M. Scordilis \\ Geophysical Laboratory, School of Geology, Aristotle University of Thessaloniki, PO Box 352-1, \\ 54006,Thessaloniki,ogalanis@lemnos.geo.auth,gr, costas@lemnos.geo.auth.gr, \\ takis@lemnos.geo.auth.gr,manolis@lemnos.geo.auth.gr
}

\section{ABSTRACT}

In the past years there has been a growing demand for precise earthquake locations for seismotectonic and seismic hazard studies. Recently this has become possible because of the development of sophisticated location algorithms, as well as hardware resources. This is expected to lead to a better insight of seismicity in the near future. A well-known technique, which has been recently used for relocating earthquake data sets is the double difference algorithm. In its original implementation it makes use of a one-dimensional ray tracing routine to calculate seismic wave travel times. We have modified the implementation of the algorithm by incorporating a three-dimensional velocity model and ray tracing in order to relocate a set of earthquakes in the area of the Mygdonia Basin (Northern Greece). This area is covered by a permanent regional network and occasionally by temporary local networks. The velocity structure is very well known, as the Mygdonia Basin has been used as an international test site for seismological studies since 1993, which makes it an appropriate location for evaluating earthquake location algorithms, with the quality of the results depending only on the quality of the data and the algorithm itself. The new earthquake locations reveal details of the area's seismotectonic structure, which are blurred, if not misleading, when resolved by standard (routine) location algorithms.

\section{INTRODUCTION}

Location is the first step that comes naturally in the study of earthquakes and reliable location is necessary for all kinds of seismological research. Today, as the development of new techniques and the advance of hardware resources allow it, the earthquake location problem is being reviewed. All modern location techniques originate in Geiger's method (Geiger 1912). This is based on first order Taylor series, that is, on the sufficiently valid hypothesis that a perturbation of the source parameters (spatial coordinates and origin time) and the resulting perturbation of the arrival times of seismic waves are linearly related. Geiger's method became of practical interest in the late 1960 s and early 1970 s, when the use of computers started to spread. The algorithm was then implemented in computer programs, notably HYPOLAYR (Eaton 1969) and HYPO71 (Lee \& Lahr 1972).

A major development in earthquake location was the introduction of the double-difference algorithm (Waldhauser \& Ellsworth 2000), which is also based on Geiger's algorithm but instead of using perturbations of arrival times (i.e. the difference between expected and observed arrival times), it employs the difference of the perturbations in arrival times from two events which occurred close to each other in space. The notion of the difference between events of the difference between expected and observed arrival times gave the name to the double-difference algorithm. It must be noted that developments towards relative earthquake location already existed before (Fréchet 1985, Got et al. 1994), however the double-difference algorithm is superior for a number of reasons: a) it uses all the data available, i.e. all pairs of earthquakes that are close enough to each other and have common phase arrivals, b) it is capable of combining phase picks made by analysts together with time-lag information calculated by waveform cross-correlation and finally, c) it is implemented in a freely distributed computer program, named hypoDD (Waldhauser 2001). 
Our modification to this algorithm is the incorporation of a three-dimensional ray tracing routine. The original program by Waldhauser (2001) assumes a layered velocity model, with a constant compressional and longitudinal wave velocity for each layer and a constant longitudinal to compressional wave velocity ratio. Although of practical use, such a ray-tracing technique is too restrictive and too different from the actual situation.

The main reason for incorporating a three-dimensional ray-tracing module to the program is not to add to the precision of the earthquake location, but more importantly, to take a step towards the use of double-difference techniques in seismic tomography. A similar approach has been proposed by Monteiller (2003) and Monteiller et al. (2003).

The area where the algorithm was tested is the Mygdonia basin, which is located in Northern Greece in the region of Central Macedonia (fig.1-left). Its bedrock is formed of Mesozoic, Paleozoic and Precambrian metamorphic rocks of the Serbomacedonian Massif and the Permian-Triassic and Jurassic low-grade metamorphic series of the Circum-Rhodope belt. To the west of the Basin lay the Mesozoic ophiolites of the Axios (Vardar) zone (Mountrakis 1985). The basin was formed in two stages (Psilovikos \& Sotiriadis 1983). The first stage, in which large scale grabens were formed, took place during Miocene, Pliocene and Villafranchian, forming continental deposits with a thickness of $350 \mathrm{~m}$ (pre-Mygdonian system). The second stage, in which smaller basins were formed, started before the end of the Villafranchian and continued during the Quaternary. The deposits of this stage have a thickness which varies from $50 \mathrm{~m}$ to $160 \mathrm{~m}$.

The current seismotectonic setting of the region is also shown in figure 1 (right) (Mountrakis et al. 2003). The basin is bounded by normal faults with a direction, which varies from NW-SE to E-W. The stress field estimated by both neotectonic and seismological methods is also shown in the same figure, where the $T$ axis has a mean direction of $\mathrm{N}-\mathrm{S}$, which spatially varies quite rapidly along the basin. Earthquakes with a magnitude of at least $M=6.5$ have been recorded in the Mygdonia Basin area. The most well-studied one is the earthquake of June $20^{\text {th }}, 1978\left(40.8^{\circ} \mathrm{N}, 23.2^{\circ} \mathrm{E}\right.$, $M_{S}=6.5, I_{\max }=V I I I+$ Stivos, Papazachos et al. 1979), which caused casualties and damage in the city of Thessaloniki. The distribution of the epicenters of recorded earthquakes for the period 1981-2003 is shown in figure 2 (right).
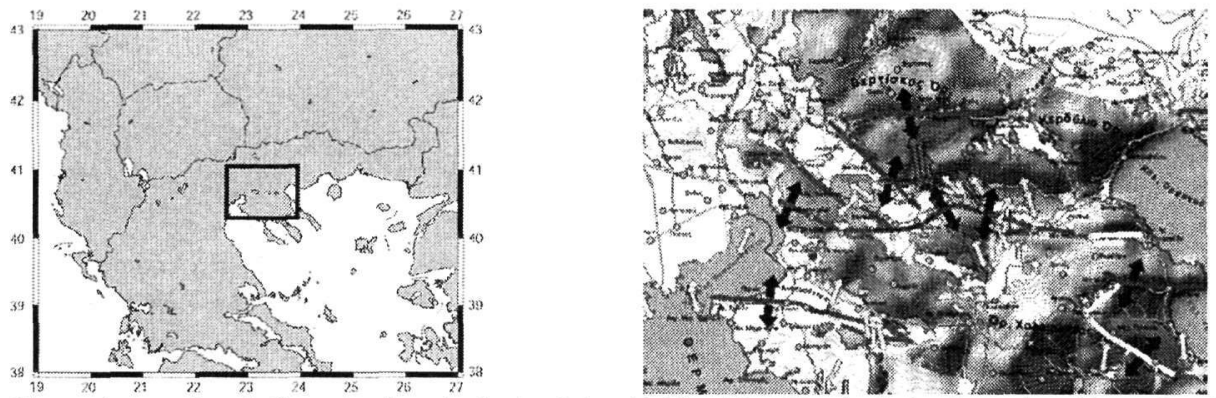

Figure 1. Location (left) and seismotectonic status (right) of the Mygdonia basin region. Lines denote seismic faults, active faults and possible active faults. Black arrows are representative $T$ axes, estimated from fault geometry and kinematics. Gray arrows are T axes calculated by the mean focal mechanisms of earthquakes.

\section{ARRIVAL DATA AND 3-D VELOCITY MODEL}

The arrival time data used in the present study were extracted from the database of the permanent seismological network of the Geophysical Laboratory of the University of Thessaloniki. Only the eight stations located closest to the Mygdonia Basin (Fig. 2, left) were used for the location. The earthquake bulletin of the network (1995-2003) and HYPO71-formatted phase files (1981-1994) were checked for errors and inconsistencies in a semi-automatic manner. Data were corrected whenever possible, otherwise were discarded and only $\mathrm{P}$ and $\mathrm{S}$ wave first arrivals were considered. Finally, the arrival information was converted to the hypoDD format. For the 3-D velocity model the one calculated by Papazachos (1998) was adopted, which has a horizontal resolution of $10 \times 10 \mathrm{~km}$ and a vertical resolution of $2 \mathrm{~km}$, extending at an area of $260 \times 240 \times 40 \mathrm{~km}$. A three dimensional visualization of this model is shown in figure $3 a$. 

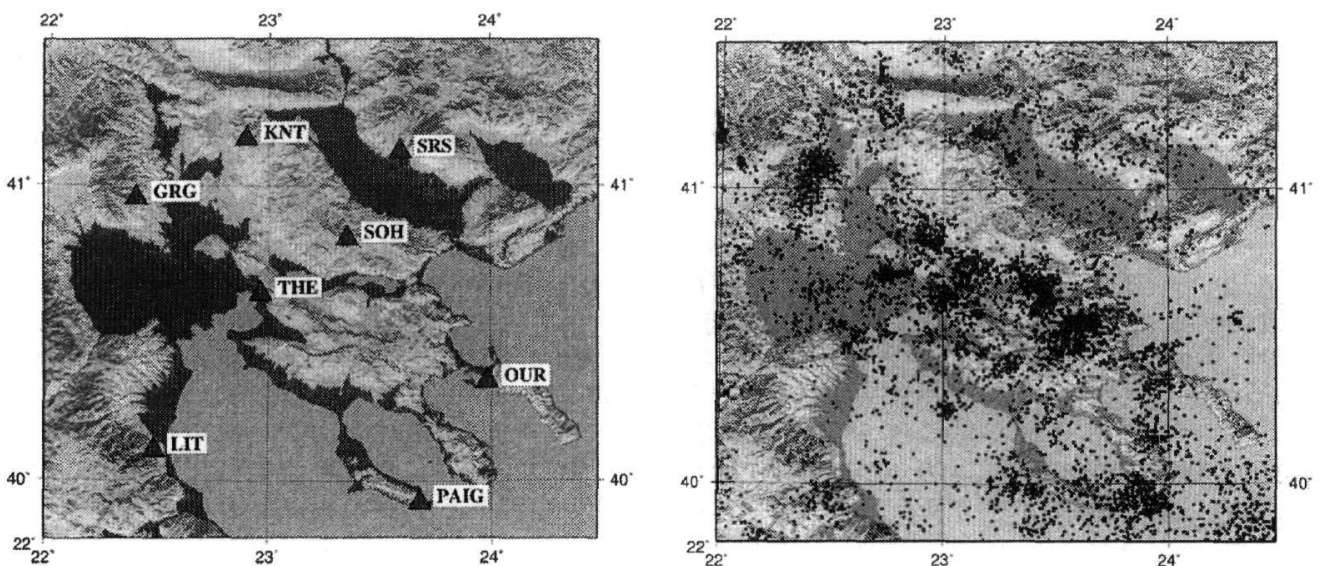

Figure 2. Stations used (left) and seismicity of the area (right). All reported earthquakes for the period 1981 2003 are shown.
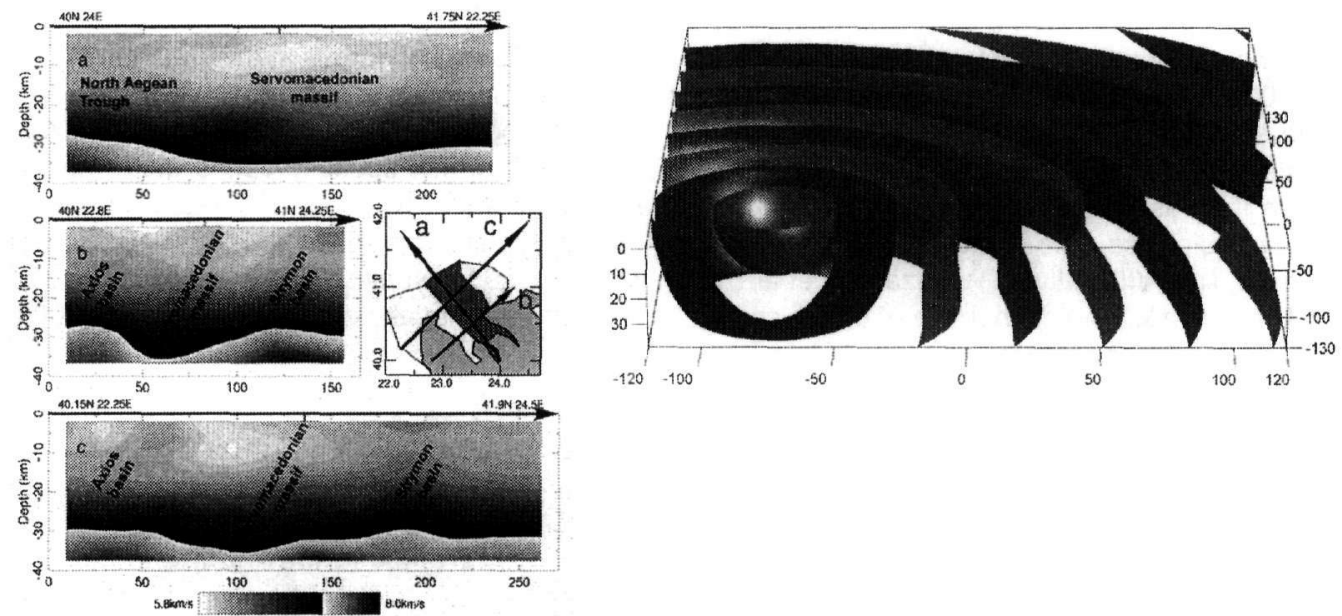

Figure 3. a) Visualization of the three dimensional P-wave velocity model used for the location of earthquakes (Papazachos, 1998). b) Travel time field for one of the stations used in this study visualized as surfaces of equal traveltime to the station.

\section{METHOD}

The 3D ray tracing employed involves a two-step process. In the first step, the ray path is calculated as the shortest path on a regular grid, using Dijkstra's algorithm for weighted graphs (Moser 1991). This algorithm takes as input a graph (i.e. a set of nods connected by edges), with a positive weight assigned to each edge. In the case of ray tracing this weight is the travel time from one nod to the next, taking into account the mean slowness between the two nods. The algorithm calculates the shortest path (the path with the minimum sum of weights from the source nod to each of the other nods). If the nods are dense enough and edges starting from each nod cover all directions, then this model sufficiently simulates the minimum travel time path. The resulting ray path produced by the first step is a first approximation of the real ray path and generally it is sufficiently close to the global travel time minimum. The second step is then performed so as to bend the ray until it reaches this "true" global travel-time minimum. This is achieved by a minimization technique based on the conjugate gradients method (Moser et al. 1992, Snieder \& Sambridge 1992).

Using this methodology for ray tracing, we have calculated the travel time field in the volume covering the velocity model, over a regular grid. The results (the travel time and its three spatial de- 
rivatives) were stored in a binary file, using the same spacing as the velocity model (10X10X2km). This calculation was repeated for every station, being the most time-consuming part of the data processing. A typical travel time field for a station is shown in figure $3 \mathrm{~b}$.

The double difference earthquake location algorithm is described in Waldhauser \& Ellsworth (2000). It is based on Geiger's method, where the system to be solved is (Aki \& Richards 1980)

$$
\mathbf{G m}=\mathbf{d}
$$

where the unknown, $\mathbf{m}$, is the perturbation to the initial model $\hat{\mathbf{a}}$, that will produce the true model $\mathbf{a}^{0}$

$$
m_{j}=a_{j}^{0}-\hat{a}_{j}
$$

$a_{j}(j=1 \ldots 4)$ are the source parameters; spatial coordinates $x, y, z$, or origin time $\tau, \mathbf{d}$ is the vector of observations, that is, observed travel time minus expected travel time (or, equivalently, observed arrival time minus expected arrival time).

$$
d_{i}=t_{i}-T_{i}(\mathbf{a})
$$

and finally $\mathrm{G}$ is a matrix, the elements of which denote what effect the $j$ th source parameter has to the $i$ th observation

$$
G_{i j}=\frac{\partial d_{i}}{\partial a_{j}}(\mathbf{a})
$$

which is equal to the spatial derivatives of travel time, in the case of the three spatial source parameters, or equal to unity, in the case of origin time. The double-difference earthquake location algorithm, subtracts equations that correspond to couples of earthquakes for which the difference in arrival time differences is known. This leads to a system of equations, similar to (1) with a new meaning for the unknowns and the data. $\mathbf{m}$ is still the perturbation to the initial model $\hat{\mathbf{a}}$, that will produce the true model $\mathbf{a}^{0}$ (equation 2) but with $j=1 \ldots 4 N$, where $N$ is the number of earthquakes being located. $\mathbf{d}$ is, still, the vector of observations, however now by observation we mean the double difference:

$$
d_{i}^{k l}=\left(t_{i}^{k}-T_{i}^{k}(\mathbf{a})\right)-\left(t_{i}^{\prime}-T_{i}^{\prime}(\mathbf{a})\right)
$$

where $d_{i}^{k l}$ is observation $i$ which involves events $k$ and $l$, and $t_{i}^{k}, T_{i}^{k}$ are observed and theoretical travel times for the event $k$. The matrix $\mathbf{G}$ is modified to fit the new problem:

$$
G_{i j}^{k}=\frac{\partial d_{i}^{k}}{\partial a_{j}^{k}}(\mathbf{a})
$$

where $d_{i}^{k}$ is observation $i$ which involves event $k$ and $a_{j}^{k}$ is source parameter $j$ of the same event $k$.

\section{APPLICATION}

To calculate the earthquake locations, equation (1) is solved iteratively. In the initial iteration the vector $\mathbf{m}$ is filled in by values taken from the earthquake catalogue. Vector $\mathbf{d}$ is constructed with the help of an auxiliary program that comes with hypoDD that takes as input a list of earthquakes with their $\mathrm{P}$ and $\mathrm{S}$ wave first arrivals and extracts all travel time differences for couples of events that conform to a number of criteria. These criteria are the distance between the two events, the distance between event pair and station and the common phases between the two events. Also the user can (and must) restrain the number of pairs used, by setting a limit on how many other events can each event be linked to, otherwise the system of equations will be too large, without containing additional information. The theoretical traveltimes needed for the calculation of the double difference are retrieved from the pre-calculated travel time field (on the regular grid) by simple interpolation. Similarly, the elements of the matrix $\mathbf{G}$ are retrieved from the same field. After each iteration, the elements of $\mathbf{G}, \mathbf{m}$ and $\mathbf{d}$ are updated, according to the new source parameters calculated.

During the progress of iterations, earthquakes can be "lost" for a number of reasons. First of all, an earthquake may not be sufficiently connected to neighboring earthquakes to allow its relocation. Another reason is that an earthquake has shifted to a position outside the $3 \mathrm{D}$ velocity model. Finally an earthquake may lose connectedness with other earthquakes because some of them were lost in previous iterations or because their new distance is too large. As a result, only a percentage of the 
earthquakes present in the original catalogue are relocated. This percentage depends mainly on the quality of the data.

Equation (1) can be solved using either Singular Value Decomposition (SVD) or a sparse-matrix conjugate gradient method such as LSQR (Paige \& Saunders 1982). LSQR is much faster for large sparse matrices (such as system 1), however only provides the solution and a rough estimation of the error. As LSQR provides no information on the singular values of the coefficient matrix, the conditioning of the system is ensured by applying a damping factor $\lambda$, to system (1) by solving:

$$
\left[\frac{\mathbf{G}}{\lambda \mathbf{I}}\right] \mathbf{m}=\left[\frac{\mathbf{d}}{\mathbf{0}}\right]
$$

In theory $\lambda$ should be equal to $\sigma_{d} / \sigma_{m}$ (Franklin, 1970), where $\sigma$ denotes standard deviation. As LSQR provides no reliable information on this, we followed Waldhauser (2001) and used an empirical rule to specify an appropriate damping factor. Thus, in each case we used a damping factor which resulted in a condition number of 40 to 80 . Tests showed that the damping factor does not affect the results significantly, provided that the condition number of equation (7) is in this range.

\section{RESULTS}

The same set of earthquakes was relocated in three different ways. At first we relocated this set of earthquakes using a $1 \mathrm{D}$ velocity model and the new three-dimensional ray-tracing module, to test its reliability. The results, for the earthquakes that were finally relocated are shown in figure $5(\mathrm{~A})$. It must be noted that only earthquakes that were successfully relocated are shown, so these maps may not reflect the true distribution of seismicity, however most of its main features are visible. Then we relocated the same set of earthquakes using the 3D velocity model (fig. 5B). The results are consistent and relatively small differences in epicenter locations can be attributed to the difference between the $1 \mathrm{D}$ and $3 \mathrm{D}$ velocity models.

In order to achieve numerical stability, the original algorithm allows the user to divide the list of earthquakes into clusters, based on a minimum number of links (common phases) among events. This pre-processing ensures that in the system of the equations, all subsets of equations will have a minimum number of unknowns in common. In the third and final step we have relocated the earthquakes, after clustering them, using a minimum number of 8 links for the clustering. This resulted in 430 clusters, the largest of which included 428 events (before relocation) and 639 isolated events. We have relocated the 50 clusters, which included the largest number of events, with the smallest clusters including 6 events. The results are shown in figure $5(\mathrm{C})$, where in addition to the events that the algorithm failed to relocate, small clusters and isolated events are also not presented.

In figure 6 the central part of the Mygdonia basin is shown in detail. The visual inspection shows that the modified double-difference algorithm has improved the locations by both producing more linear distributions of seismicity (delineating active faults) and "migrating" epicenters to their (presumably) correct position due to the use of a $3 \mathrm{D}$ velocity model. A very clear delineation of the Arnaia 1995 sequence is found in figure $6(B)$, compared to the rather diffuse distribution of figure $6(A)$. Similar changes are observed for the Asvestochori seismicity close to Thessaloniki, the recent sequence south of Thermi, the seismicity in the Langadas lake area and the activation of the Ag.Athanasios area to the NW of Thessaloniki. A less clear delineation is observed for the Volvi area events. It should be pointed out that the "migration" of epicenters due to the use of a 3D model varies spatially, demonstrating the usefulness of its use for accurate absolute and not only relative relocations. However, it must be emphasized that this improvement only concerns the percentage of earthquakes that were successfully relocated and which must have been sufficiently well located in the first place. To evaluate the usefulness of the relocation process in determining the features of the spatial distribution of earthquakes, the results should be compared to the catalogue locations shown in figure 2 . 


\section{A. 1D velocity model}

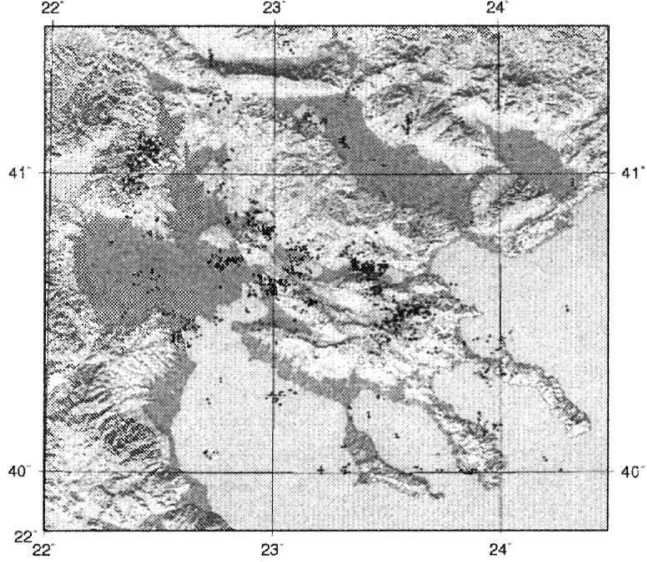

B. 3D velocity model, without clustering

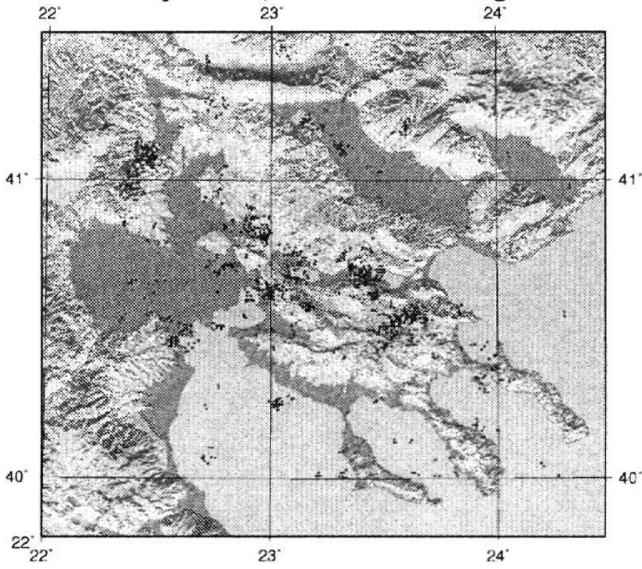

C. $32^{\circ}$ velocity model, with clustering

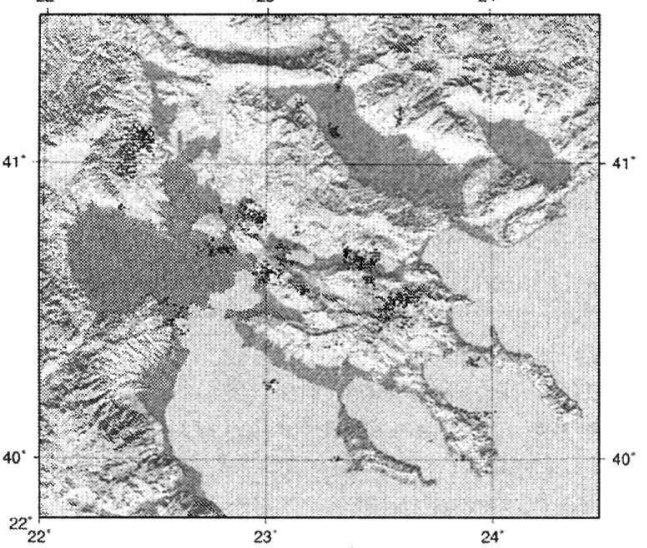

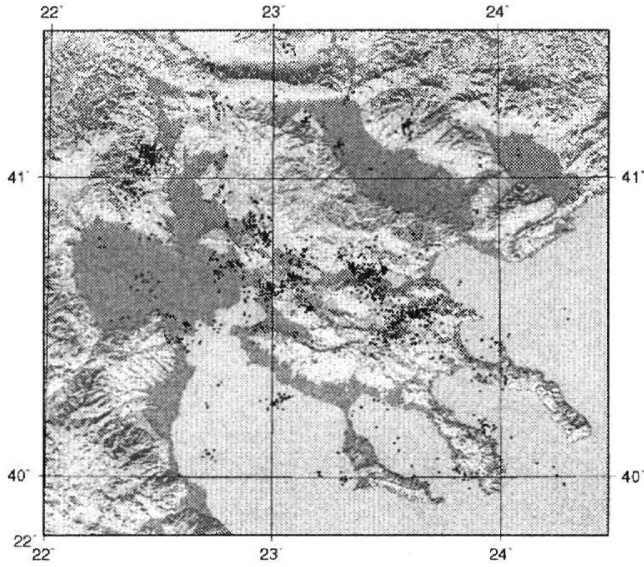
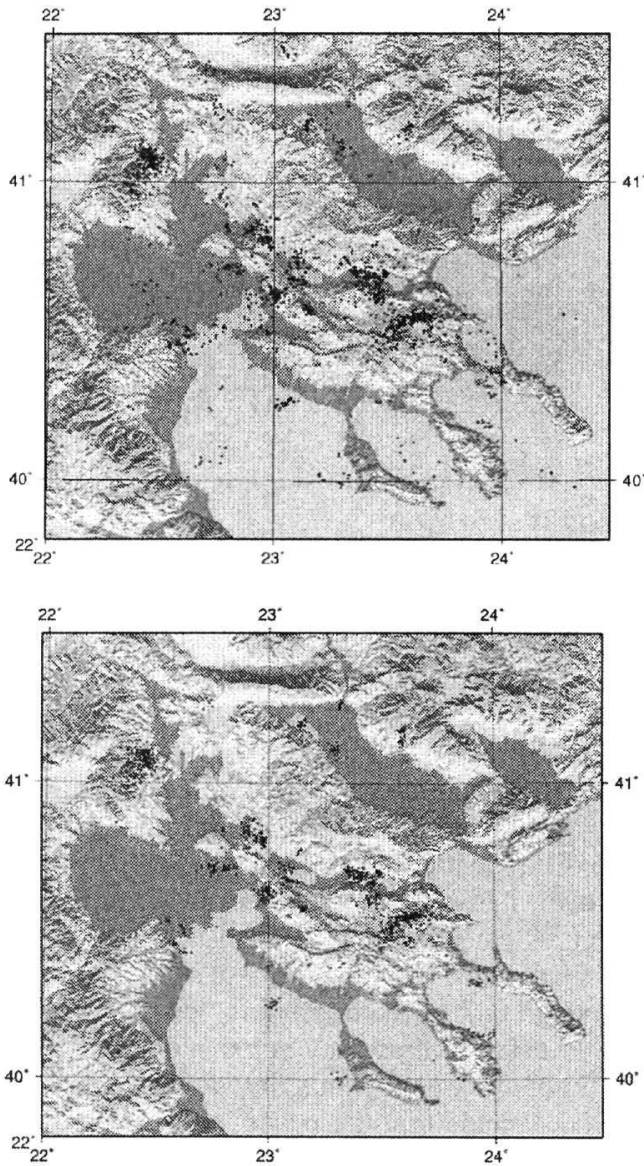

Figure 5. Comparison of the original catalogue locations with the revised relocations. In the top row (A) the results of relocation using a 1D velocity model are shown. In the middle row (B), the results of relocation using the 3D velocity model, without any clustering are presented. Finally, in the bottom row (C), the results of relocation for the 50 clusters which contained the largest number of events, using the 3D velocity model are shown. 


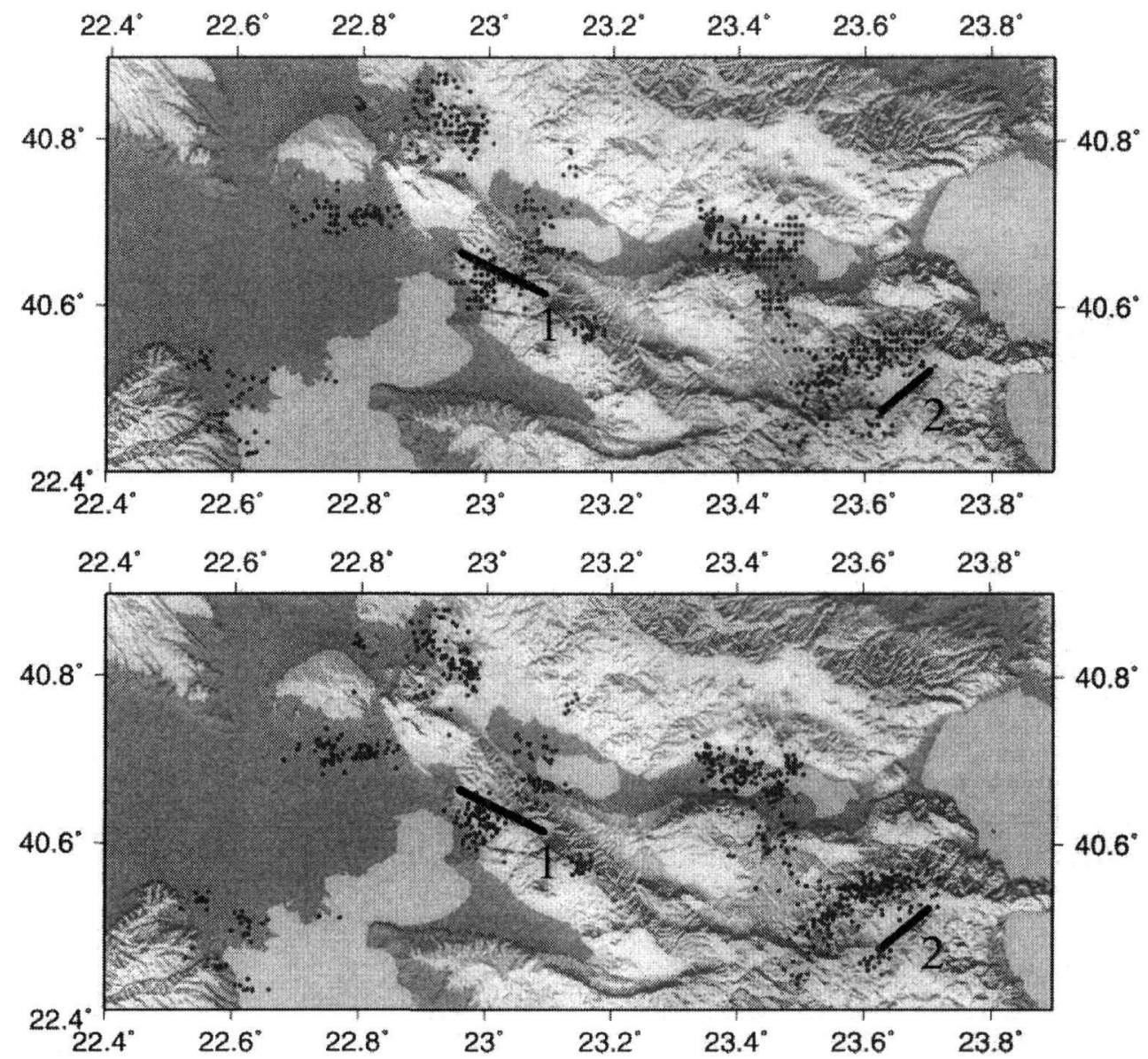

Figure 6. Comparison of the original catalogue locations with the revised relocations for the Mygdonia Basin. On the top the original catalogue locations are presented, while in the bottom figure the revised relocations using the modified double difference algorithm are shown. The positions of the faults of Asvestochori and Arnea are denoted by lines 1 and 2 respectively.

To evaluate the effect of the relocation on the depth distribution of earthquakes, six profiles were drawn and studied across the broader Mygdonia basin area (Fig. 7). In every case the relocated events show more recognizable faulting patterns, especially along some faults $(A, B, C, F)$. In several cases the normal faults that dominate the study area exhibit a near-vertical dip (A, B, E, F). However, this is not always the case, as is seen by the impressive depth-section of the Asvestochori fault seismicity (fig.7C), which clearly dips under the city of Thessaloniki at depths between 2 and $8 \mathrm{~km}$, with a dip angle of $\sim 50-55^{\circ}$. These results are in excellent agreement with the 1999 Asvestochori fault sequence presented in the same figure from Papazachos et al. (2000), which was located using a temporary deployment (solid triangles at the right-hand side of fig. $7 \mathrm{C}$ ). The excellent agreement of the fault characteristics as these are revealed by the permanent and temporary network verifies that the proposed approach can achieve comparable accuracies between the regional network and temporary-local deployments.

The Ag. Athanassios seismicity shows a near vertical fault (fig.7A), slightly dipping to the south. The main Arnaia fault zone (fig.7F) also dips steeply to the south, while the recent Thermi sequence extends between 2 and $12 \mathrm{~km}$, steeply dipping to the north. It is interesting to notice that the Volvi seismicity (fig.7E) shows a more complicated pattern, probably due to the activation of several neighboring faults. 


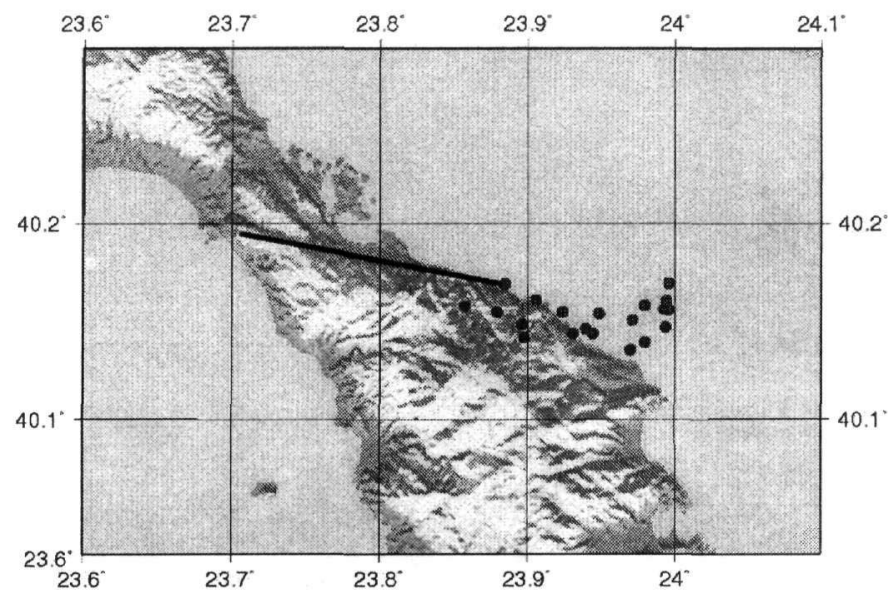

Figure 8. Extension of the Vourvourou neotectonic fault towards the east, as is delineated by the relocated seismicity using the 3D model double-difference technique.

Except for the Mygdonia basin area, interesting results are also obtained for all faults of the broader Mygdonia basin area, such as the Griva 1990 fault seismicity (NW cluster in figure 5). An interesting continuation of the observed Vourvourou neotectonic fault is seen in figure 8 , where the eastern section of the fault clearly continues in the sea towards the east. Such results further confirm the usefulness of relative relocation using double-difference in a 3D velocity model for identification of active faults and their correlation with independent (e.g. neotectonic) information.

\section{CONCLUSIONS}

The results obtained in the present work demonstrate that 3D ray tracing can be efficiently incorporated in relative location algorithms, resulting in more accurate both relative and absolute locations. The proposed modification can expand the application of double-difference algorithms in seismic tomography. The method has been successfully applied in the Mygdonia basin area, allowing the better description of the geometrical characteristics of several active faults, including the Asvestochori fault close to the city of Thessaloniki, in very good agreement with previous studies for this fault (e.g. Papazachos et al., 2000). Further improvement of the results can be obtained by using time lags from waveform cross-correlation, as the relative difference in traveltime is exactly what is needed for the double difference algorithms. Another way to improve the results would be to use better-located hypocenters as a starting point, for example by performing a preliminary relocation of the events using station corrections. The applied method is currently under revision and is going to be further improved and fine-tuned in the future by the incorporation of additional tomographic terms in equation (1).

\section{ACKNOWLEDGEMENTS}

The GMT software (Wessel and Smith, 1995) was used to generate most of the maps of this study. This work has been partially supported by the EC EuroSeisRisk (Res. Comm. AUTH project 20242) and the Greek Ministry of Education HERACLITUS (EPEAEK) (Res. Comm. AUTH project 21761) projects.

\section{REFERENCES}

Aki, K. and Richards, P.G., 1980, Quantitative Seismology, vol. II, W.H. Freeman and Company, 932pp.

Eaton, J. P., 1969, HYPOLAYR, a computer program for determining hypocenters of local earthquakes in an earth consisting of uniform flat layers over a half space, U.S. Geological Survey Open-File Report, $155 \mathrm{p}$. 
Franklin, J.N., 1970. Well-posed stochastic extensions of ill-posed linear problems, J. Math. Anal. Appl., 31, 682-716.

Fréchet, J., 1985, Seismogenesis and seismic doublets, Ph.D. thesis, Scientific and Medical University of Grenoble, 206p. (in French).

Geiger, L., 1912. Probability method for the determination of earthquake epicenters from the arrival time only, (translated from Geiger's 1910 German article) Bulletin of St. Louis University, 8 (1), p. 56-71.

Got, J.-L., Fréchet, J., and Klein, F.W., 1994, Deep fault plane geometry inferred from multiplet relative relocation beneath the south flank of Kilauea, J. Geophys. R., 99, 15375-15386.

Lee, W. H. K., and Lahr, J. A., 1972, HYPO71: a computer program for determining hypocenter, magnitude and first motion pattern of local earthquakes, U.S. Geological Survey Open-File Report, 100 p.

Monteiller, V., 2003, High Resolution Tomography with the aid of seismic multiplets, Ph.D. thesis, Joseph Fourier University, Grenoble (in French).

Monteiller, V., Got, J.-L., Virieux, J. and Okubo, P.G., 2003, Double Difference Tomography of Kilauea Volcano, Hawaii, Geophysical Research Abstracts, 5, 05974.

Moser, T.J., 1991, Shortest path calculation of seismic rays, Geophysics, 56, 59-67.

Moser, T.J., Nolet, G., Snieder, R., 1992, Ray Bending Revisited, Bulletin of the Seismological Society of America, 82, 259-288.

Mountrakis, D.M., 1985, Geology of Greece, University Studio Press, Thessaloniki, 208 pp. (in Greek)

Mountrakis, D., Kilias, A., Tranos, M., Thomaidou, E., Papazachos, C., Karakaisis, G., Skordilis, E., Hatzidimitriou, P., Papadimitriou, E., Vargemezis, G., Aidona, E., Karagianni, E., Vamvakaris, D. and Skarlatoudis, A., 2003, Determination of the characteristics and the seismotectonic behavior of the main seismic-active faults of the Northern Greece Area with the use of neotectonic and seismic data, Earthquake Planning and Protection Organization (OASP). (in Greek)

Paige, C.C. and Saunders, M.A., 1982, LSQR - an algorithm for sparse linear equations and sparse least squares, ACM Transactions on Mathematical Software, 8, 43-71.

Papazachos, B., Mountrakis, D., Psilovikos, A. and Leventakis, G., 1979, Surface fault traces and fault plane solutions of May-June 1978 major shocks in the Thessaloniki area, Greece. Tectonophysics 53, 171-183.

Papazachos, C., 1998, Crustal P- and S-velocity structure of the Serbomacedonian Massif (Northern Greece) obtained by non-linear inversion of traveltimes, Geophys. J. Int., 134, 25-39.

Papazachos, C., Soupios, P., Savvaidis, A. and Roumelioti, Z., 2000. Identification of small-scale active faults near metropolitan areas: An example from the Asvestochori fault near Thessaloniki, Proc. XXVII ESC General Assembly, Lisbon, 10-15 September, 221-225.

Psilovikos, A and Sotiriadis, L., 1983, The neotectonic graben complex of the Sevomacedonian massif at the area of Promygdonia basin, in northern Greece, Clausthaler Geologische Abhandlungen, 44, 21-53.

Snieder, R. and Sambridge, M., 1992, Ray perturbation theory for traveltimes and ray paths in threedimensional heterogeneous media, Geophysical Journal International, 109, 294-322.

Waldhauser, F., 2001, hypoDD - A program to compute double-difference hypocenter locations, U.S. Geol. Survey Open File Report 01-113, 25pp.

Waldhauser, F. and Ellsworth, W.L., 2000, A double-difference earthquake location algorithm: Method and application to the northern Hayward fault, Bull. Seism. Soc. Am., 90, 1353-1368.

Wessel, P. \& Smith, W. 1995. New version of the Generic Mapping Tools. EOS Trans. Amer. Geophys. U., $76: 329$ 